Monográfico / Monographic

\title{
Democracia y creatividad. El nuevo horizonte de la política en el siglo XXI
}

\author{
Democracy and Creativity. The New Horizon of Politics in the \\ Twenty-First Century
}

\author{
Juan María Sánchez-Prieto \\ I-COMMUNITAS: Institute for Advanced Social Research, Universidad Pública de Navarra, España. \\ juanma.sanchez@unavarra.es
}

Recibido / Received: 17/04/2020

Aceptado / Accepted: 26/06/2020

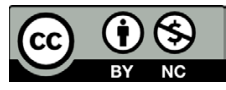

\section{RESUMEN}

Desde 2008 se registra un cambio de clima político. ¿Es posible reinventar la democracia o estamos abocados a la post-democracia? El nacional populismo revela una crisis de confianza ante el futuro, la fuerza de un presentismo dramático: el aquí y ahora, el nosotros primero, donde se abre paso la posverdad, capaz hoy de fabricar no ya un mito, una mentira, una ficción, sino una nueva voluntad general al margen del contrato social. La consolidación de hiperlíderes con enorme dificultad en la práctica para entender un poder condicionado, y que reducen la política al simple juego performativo y cortoplacista, puede acabar consagrando paradójicamente la soberanía del algoritmo como nueva fuente de autoridad y las dictaduras digitales. El desarrollo de la conciencia humana es fundamental para el renacimiento democrático, como ha hecho ver la crisis del COVID-19 apuntando la necesidad de democracias más conscientes y resilientes. La libertad es autolimitación consciente. También apertura compasiva al sufrimiento humano y social. El momento actual requiere líderes y gobiernos más reflexivos y virtuosos, capaces de conjugar la libertad de uno con la del otro próximo y

\section{ABSTRACT}

Since 2008 we face a change in the political climate. Is it possible to reinvent democracy or are we bounded to face a new postdemocratic political turn? The national populism reveals a crisis of confidence in the future, the strenght of a dramatic presentism, the tyranny of here and now, where the us goes first, where infiltrates a postruth being able to manufacture not now a myth, a useful lie, a fiction, but a new general will apart from the social contract. The consolidation of hiperleaders with great difficulties to understand a type of limited power who reduce politics into a simple performative short-term game can paradoxically strengthen the sovereignty of the algorithm as a new source of authority in a sort of digital tyranny. The development of human consciousness is indispensable for a democratic revival as the crisis of the COVID-19 has shown us. We have to move towards selfaware and resilient forms of democracy. Freedom is an aware self-limitation. Also it is necessary a compassionate openness to forms of human and social suffering. The present moment is in need of leaderships and governments more reflexive and resilient, being able to combine the own's liberty with

Sugerencia de cita / Suggested citation: Sánchez-Prieto, J. (2021). Democracia y creatividad. El nuevo horizonte de la política en el siglo XXI. Revista Española de Sociología, 30 (1), a08. https://doi.org/10.22325/fes/res.2021.08 
lejano, donde entran también los derechos de las generaciones futuras. La juventud como tal deberá implicarse en la defensa de la democracia como lo está en la causa del planeta.

Palabras clave: democracia; creatividad; biotecnología; algoritmo; performatividad; posverdad; hiperliderazgo; conciencia; resiliencia; COVID-19. the other's liberty and with the liberty of those to come, with the future generations. The young generation must engage herself in the defense of democracy as already is in ecological issue.

Keywords: democracy; creativity; biotecnology; algorithm; performance; postruth; leadership; awareness; resilience; COVID-19.

\section{INTRODUCCIÓN}

En los últimos años han aumentado las inquietudes y preguntas acerca del futuro de la democracia. Hemos pasado del optimismo de los años 1990 al malestar y decepción actuales. ¿Asistimos a un cambio de clima político? ¿Ha entrado en crisis la democracia después de la Gran Recesión? Este artículo pretende profundizar en las razones de ese malestar, así como en las implicaciones políticas de grandes desafíos del momento como son la biotecnología o la ciencia de datos, valorando hasta qué punto la democracia tiene respuestas innovadoras para ellos, o si constituyen más bien una nueva y seria amenaza contra ella. La cuestión de fondo es la capacidad de la democracia para reinventarse a sí misma.

No es posible abordar en unas pocas páginas esta problemática en profundidad. El objetivo de este trabajo sólo es trazar un mapa aproximado de este debate. Para ello, se atiende en primer lugar a los principales diagnósticos realizados sobre el futuro de la democracia, a modo de prospección área. En segundo lugar, se desciende a la exploración de diferentes lugares entendidos como nuevas amenazas a la democracia, analizando algunas de las respuestas creativas que se han dado, no necesariamente satisfactorias desde la lógica del procedimiento y los valores democráticos. Fenómenos abusivos como el hiperliderazgo, la performatividad o la posverdad acaban por acrecentar los temores sobre los efectos de la revolución tecnológica en el crecimiento de la desigualdad social o el desplazamiento de la autoridad a los algoritmos.

En tercer lugar, se presentan algunas propuestas que, en el reverso de este debate, parecen definir un nuevo horizonte político: ¿caminamos hacia una democracia más consciente y resiliente? En la búsqueda de nuevas claves para el necesario fortalecimiento de la cultura política democrática en el siglo XXI, la crisis del COVID-19 no ha venido sino a relanzar el debate y la reflexión, concediendo nueva actualidad a los derechos humanos como moral colectiva y fuente de inspiración creativa en el actual proceso de reconstrucción democrática y social.

\section{DIAGNÓSTICOS SOBRE EL FUTURO DE LA DEMOCRACIA}

Sin obviar la complejidad apuntada, algunos debates permiten centrar la cuestión. La obra central de Bobbio (1986) preguntándose por las transformaciones de la democracia y sus dificultades de adaptación al presente, pese a la pertinencia de sus análisis, se vio enseguida sobrepasada por el súbito cambio de telón que supuso la caída del muro de 
Berlín y el derrumbe del llamado socialismo real. Son conocidas las tesis mantenidas a principios de los años 1990 por Fukuyama $(1989,1992)$ y Huntington $(1993,1996)$. Para el primero aquel hecho constituía el fin de la historia: el capitalismo se alzaba como un horizonte irrebasable. No cabía otro futuro cierto que la progresiva expansión de la democracia capitalista, la globalización económica a impulsos del neoliberalismo. A esa imagen de Fukuyama, Huntington contrapuso el choque de civilizaciones, la ineluctable confrontación de Occidente con el fundamentalismo islámico, irreconciliable con los valores democráticos fuera de la libertad de mercado. Hechos posteriores como la evolución capitalista de China, y su inserción en el nuevo orden mundial, o el fracaso del Estado islámico estarían dando la razón a Fukuyama. El contrapunto en aquel debate lo puso Michel Albert (1991), aunque pasara desapercibido: de qué democracia capitalista hablamos, planteaba, oponiendo el capitalismo individualista americano al capitalismo social europeo. Autores como Goldfarb (2001) han vuelto sobre la necesidad de pensar una alternativa al capitalismo neoliberal, ilustrando los cambios de 1989 en el este europeo como una manifestación de la creatividad de lo político.

Dos fechas principales conducen al escenario actual. La primera, 2008: el inicio de la Gran Recesión y de la crisis de Europa, que comprometió con su política de austeridad y recortes en los servicios públicos la noción de ciudadanía social, la base del modelo del Estado de bienestar construido después de 1945 y principal distintivo europeo hasta entonces. La segunda fecha es 2016 con el planteamiento del Brexit, la salida del Reino Unido de la UE, y la llegada de Donald Trump a la presidencia de EE. UU., hechos que muestran el alcance de la ola de desencanto. Las esperanzas democratizadoras que habían suscitado los novísimos movimientos sociales desde 2010, parecen haberse desvanecido, cuestionándose su efectividad ${ }^{1}$. La crisis de confianza afecta a la propia idea de futuro. Para muchas personas este ha quedado fuera del alcance de sus vidas o entienden que están condenadas, por la misma aceleración y presión del tiempo, a no tenerlo o al simple desastre (Rosa, 2016). Una percepción que la reciente crisis del coronavirus -2020: una tercera fecha inesperada- no ha hecho sino reavivar.

\section{Democracia monitorizada y agonismo}

En este periodo se multiplican los títulos sombríos sobre la democracia. La revisión efectuada por Keane (2018 [2009])-valorando los diferentes tipos de democracia, sus ideales, características y flujos históricos- desemboca en la idea de democracia monitorizada, forma gestada en la segunda mitad del siglo XX que adquiere mayor predicamento en las democracias actuales gracias a las potencialidades de las nuevas tecnologías de comunicación digital para transformar los mecanismos de la democracia representativa. La conciencia de crisis empuja a un modelo ampliado de participación ciudadana (más allá de las elecciones y los partidos) que enfatiza el papel político de la sociedad civil (y por ende de los movimientos sociales) como contrapoder, sensible a los fallos del sistema democrático y los abusos de poder (Feenstra, 2016)2. La democracia monitorizada es una invitación a la construcción por parte de la ciudadanía y sus representantes de nuevos mecanismos de escrutinio público para la restricción del poder arbitrario (institucional, económico, político), con el objeto último de afianzar el espíritu de la democracia. Sin ignorar las tendencias oscuras, la capacidad manipuladora y seductora inherente a los

1 El número 28 (2019) de la Revista Española de Sociología recoge un interesante debate sobre los resultados y consecuencias de los movimientos sociales en este contexto.

2 Una aplicación de ese marco teórico a la escena política española de 2009-2015, al tiempo que se utiliza el caso español para avistar hacia donde se dirigen las democracias actuales, puede verse en Feenstra, Tormey, Casero y Keane (2016). En cualquier caso, la reflexión actual sobre los movimientos sociales relativiza sus resultados inmediatos en la política institucional pues el propósito de muchos de ellos en la última década ha sido cuestionar la centralidad de esa política en el modelo defendido de democracia (Pleyers y Álvarez-Benavides, 2019). 
nuevos poderes y contextos de la comunicación para establecer una vigilancia organizada sobre las personas (Keane, 2013).

Partiendo de que ninguna forma de sociedad no democrática se presenta hoy como verdadero adversario de la democracia, Todorov (2012) ha insistido en la capacidad de la democracia para generar por sí misma fuerzas que la amenazan desde dentro (el ultraliberalismo, el populismo, el mesianismo), siendo estas más desestabilizadoras que los embates de los enemigos de fuera. Para Gascón (2018), el regreso de algunas amenazas para el futuro democrático que se creían superadas (como el nacionalismo secesionista), son consecuencia del golpe posmoderno. Más que nunca se hace necesario comprender la democracia, haciendo un esfuerzo por adecuar su teoría y la práctica política a los niveles actuales de complejidad social (Innerarity, 2019). Pero sin olvidar lo que de verdad la convierte en un proyecto perdurable, la voluntad de que el interés común sea definido por el conjunto de la sociedad, buscando la máxima identificación entre gobernantes y gobernados para perseguirlo, lo que implica volver a hacer de la política el arte de conciliar la voluntad de todos, un bien común, subraya Olalla (2017) forzando la paradoja: el futuro de la democracia es un viejo futuro.

Mouffe $(2003,2014)$ ha insistido en los límites de todo consenso racional y en la inevitabilidad del conflicto en la concepción de "lo político"; noción que distingue de "la política" como conjunto de prácticas e instituciones encaminadas a la instauración de un orden, que no puede darse sino en condiciones conflictivas al quedar afectadas por lo político. La cuestión crucial de la democracia no es llegar a un consenso racional sino establecer una distinción nosotros/ellos compatible con el pluralismo, de manera que el conflicto no se entienda en términos de antagonismo (la dialéctica amigo/enemigo, central en la crítica de Carl Schmitt a la democracia liberal) sino en forma de agonismo (donde el adversario y la confrontación entre adversarios definan la categoría principal de la política democrática). El consenso necesario en torno a las instituciones democráticas y los valores que han de informar la comunidad política no puede ocultar el disenso, las ineludibles discrepancias sobre el significado de esos valores y la manera de implementarlos ${ }^{3}$.

Mouffe reivindica el componente pasional de la política y la necesidad de que las pasiones encuentren formas de identificación democráticas para evitar tanto el desarrollo de políticas esencialistas de carácter nacionalista o religioso como la confrontación sostenida en valores morales no negociables. Desde esta perspectiva, reprueba que la respuesta actual al auge de los populismos se haga en términos de condena moral, estableciendo un cordón sanitario entre ellos y los buenos demócratas, porque así se renuncia a su combate político. Tanto la ilusión del modelo consensual (afirmación exclusiva de la razón, del consenso, de la moderación) como la comodidad del antagonismo moral (que renuncia a encauzar democráticamente los sentimientos y pasiones sociales) impiden el desenvolvimiento de una esfera pública agonística. Son, a su juicio, dos formas distintas de post-política que "están poniendo en peligro la democracia, al propiciar un marco para la emergencia de antagonismos que no serán manejables por las instituciones democráticas" (Mouffe, 2010, p. 16).

Los escenarios de futuro que contempla Mouffe no son menos sombríos llevados al orden mundial. Discursos como el advenimiento de una democracia cosmopolita o el establecimiento de una República mundial vienen a justificar la preeminencia de Occidente (y del orden económico neoliberal) o a negar la dimensión de lo político consustancial a cualquier sociedad. La hipótesis misma de un poder dominante que anulase las diferencias favorecería el choque de civilizaciones que se afirma querer evitar. Es preciso promover una nueva concepción del orden mundial, "conscientes de los peligros implícitos en las

3 En cualquier caso, sea por la vía del consenso racional o por la sedimentación de prácticas sociales dominantes, se llega a la misma necesidad de definir el espacio del conflicto legítimo dentro de una sociedad plural, por porosa que sea la frontera entre el conflicto civil e incivil: la democracia no es capaz de albergar cualquier tipo de disenso. 
ilusiones de un discurso universalista-globalista", un nuevo orden multipolar donde una "pluralidad de formas de democracia sea considerada legítima". Retomando el debate Fukuyama-Huntington, aun sin referirse a él, frente al enfoque universalista que conduce a una confrontación antagonística entre diferentes civilizaciones, Mouffe aboga por una "coexistencia agonística entre diferentes polos regionales con sus instituciones específicas" (Mouffe, 2010, pp. 18-19; 2014, cap. 2).

\section{¿Post-democracia?}

¿El acecho de la post-política nos aboca irremediablemente a la post-democracia, a una agónica degeneración de la democracia representativa de consecuencias imprevisibles, como ha venido a sugerir Crouch (2004)? La crisis de 2008 ha extendido, a impulsos de los movimientos sociales, la imagen de una democracia actual devaluada, que mantiene las formas democráticas, pero desprecia el debate público y consagra modalidades de política y gobierno dominadas por élites privilegiadas y corporativas, que escapan a cualquier control, más propias de épocas predemocráticas. Lo que para algunos mentores de movimientos innovadores como el 15-M español, justificaría, "frente al pesimismo de la nostalgia, el optimismo de la desobediencia". El nuevo impulso democratizador no pasa por un regreso al pasado sino por "una posdemocracia enfadada que entiende que no existe la posibilidad de recuperar el gobierno de las mayorías sin recuperar el conflicto" (Monedero, 2012, p. 85).

Para Sintomer, en una era de ruptura como la presente "los tiempos de las pequeñas reformas han pasado", y sólo con mayor arrojo "se podrán evitar los escenarios de posdemocracia y autoritarismo" -las dos tendencias más significativas de la política del siglo XXI a nivel global- "o incluso el colapso". "Es necesaria una verdadera revolución democrática", abierta a muchas vías constitucionales y sociales, que cambie la lógica de la gobernanza actual y favorezca la creación de coaliciones amplias y flexibles donde confluyan actores diversos en la defensa de objetivos en parte heterogéneos desde la convicción de que las dinámicas democráticas han sido siempre "híbridas, mestizas, plurales". Y concluye: "El siglo XXI no se anuncia como el final de la historia, sino como una época agitada. Se experimentarán numerosas transformaciones. Tal vez para peor. Pero nada permite afirmar que lo mejor quede automáticamente excluido" (Sintomer, 2017, pp. 27, 32-34). La crisis del COVID-19 reforzaría este argumento.

A la vista de esta muestra de autores, ¿nos hallamos, como en épocas pasadas, ante el pesimismo de los teóricos o contamos con un refrendo empírico? Los datos no son tranquilizadores a tenor de los informes sobre la democracia de The Economist. Entre 2008 y 2018 se registra un cambio de clima político, un retroceso de la democracia, gráficamente visualizada en sus mapas 4 : los colores calientes correspondientes a los regímenes autoritarios van ganando intensidad, mientras los fríos que identifican a los plenamente democráticos rebajan su tono. La realidad que presenta el ranking de Freedom House no es diferente. El informe de 2008 anota un considerable revés para los derechos políticos y las libertades civiles en todo el mundo, un "deterioro perturbador". El de 2010 acentúa la "erosión global" (Freedom House, 2012); el de 2011 habla de "desafío autoritario a la democracia" (Puddington, s. f.); el de 2016 titula "Dictadores ansiosos, democracias vacilantes: la libertad global bajo presión" (Puddington y Roylance, 2015); “Populistas y autócratas: la doble amenaza a la democracia mundial" señala el de 2017 (Puddington y Roylance, 2016); y los de 2018 y 2019 consideran ya abiertamente a la "democracia en crisis" (Abramowitz, 2017) y a la "democracia en retirada" (Freedom House, 2018), respectivamente.

\footnotetext{
4 The retreat of global democracy stopped in 2018 (2018). Véanse, por ejemplo, los correspondientes a 2008, 2012 y 2018.
} 
La imagen inmediata a la crisis del coronavirus es pues perturbadora. ¿Cabe una reinvención de la democracia? Más allá de los indicadores que manejan esos índices, ¿se pueden identificar las causas del malestar democrático y las nuevas amenazas a la democracia? La democracia es un sistema que no cesa de cuestionarse a sí mismo. La crítica permanente es fuente también de creatividad aunque no por ello las respuestas creativas que hayan podido o pueden darse, deban resultar satisfactorias.

\section{NUEVAS AMENAZAS A LA DEMOCRACIA}

Una figura de entresiglos como Mary Parker Follet, hace 100 años, resulta cercana a nuestros días cuando afirmaba que los desafíos del momento no son retos técnicos o tecnológicos sino fundamentalmente de adaptación para capitalizar la complejidad social y la pluralidad de miradas, que no deben ser vistas como fuente de problemas sino de soluciones. Invitaba a profundizar en la democracia y a aprovechar la fuerza integradora de la creatividad para mejorar nuestra capacidad de respuesta a la situación dada, haciendo del cambio un proceso de co-creación entre diferentes informado por las diferencias (Nelson, 2017). Hoy, sin embargo, esto no es posible sin tener muy presentes los riesgos e implicaciones políticas de la nueva revolución tecnológica, inimaginables hasta hace poco, y que arrojan nuevas sombras sobre los efectos de la globalización.

\section{Nuevos horizontes de desempleo y desigualdad}

Si la experiencia de la Gran Recesión provocada por la financiarización de la economía agravó la crisis de la ciudadanía laboral (Alonso, 2007), las nuevas incertidumbres en torno a la guerra comercial China-EE. UU., la desaceleración de Europa y ahora el coronavirus han aumentado la inquietud sobre el impacto de la automatización y la inteligencia artificial (IA) en el mundo del trabajo. El temor no es nuevo, desde el ludismo ha acompañado a las revoluciones industriales, pero debates controvertidos como la renta básica universal parecen anunciar hoy el advenimiento de una sociedad post-laboral, de consecuencias inmediatas para el desempleo. Atendiendo a las nuevas formas de la robótica, el crecimiento exponencial de la IA puede ser devastador en el mercado de trabajo (Niewiadomski y Anderson, 2017). Por encima de modelizaciones matemáticas que aventuran a largo plazo un crecimiento económico equilibrado, más ajustado al "cambio estructural habitual" en la evolución de la humanidad que al "fin del trabajo" (Vermeulen, Kesselhut, Pyka y Saviotti, 2018), en el mundo real la revolución de la IA hará más profundas las desigualdades exigiendo respuestas innovadoras desde las políticas públicas (Kim, 2019).

El nuevo horizonte constituye un reto para la creatividad económica. Podrían surgir nuevos emprendedores, campos de actividad y empleos que favorezcan mejor el desarrollo humano, incentivando el ocio y la cultura como ya planteara en los años 1960 la crítica de Marcuse a la sociedad industrial avanzada (Sánchez-Prieto, 2014), aunque esto pueda considerarse utópico de nuevo. La realidad es que sin crecimiento económico no hay derechos sociales, esa es la gran amenaza que pesa sobre Europa y el Estado de bienestar del siglo XXI. Las llamadas de algunos gobiernos a propiciar un nuevo modelo productivo basado en $\mathrm{I}+\mathrm{D}+\mathrm{i}$ se revelan como un discurso mágico, bien porque no son conscientes aún del alcance de la tecnología disruptiva, o porque instalados en el cortoplacismo menosprecian las consecuencias que la pérdida de la ciudadanía laboral entre los más débiles, con la consiguiente dificultad para afrontar el futuro, pueda entrañar para el propio devenir de las democracias. 
Cabe apuntar igualmente un horizonte de desigualdad biológica, no menos inquietante. El aumento considerable de la esperanza de vida, particularmente en las sociedades avanzadas, unido a los programas de mejora de las condiciones físicas y cognitivas o de prevención de enfermedades que aseguran el alargamiento de la vida humana, a los que no todos ni en todas partes se puede acceder (Bogomiagkova, Orekh y Lomonosova, 2016), harán que los ricos en el horizonte inmediato de 2050 o de finales de siglo XXI estén más dotados y sean más creativos e inteligentes que los pobres (Harari, 2018, p. 98). ¿Es compatible la democracia con un régimen de castas biológicas? La bioingeniería y la IA pueden dar nueva actualidad a Nietzsche dividiendo la sociedad entre una pequeña clase de superhombres y una multitud de esclavos o seres vulgares. El mundo ficticio de Huxley se vuelve real (los hombres probeta de su novela de 1932, concebidos por máquinas, generaban una nueva jerarquía social donde arriba y abajo se sitúan quienes genéticamente están destinados a mandar y a ser esclavos). Las posibilidades actuales de las biotecnologías en la planificación de la vida y de los fármacos psicotrópicos en la alteración de la inteligencia crítica y la conciencia, ¿nos abocan a la dimensión de "humanos de criadero" y a la zoopolítica? (Bodei, 2007).

Los conceptos de biopolítica y biociudadanía, de impronta foucaultiana, privilegiando no las personas singulares sino sus rasgos biológicos tratados estadísticamente para poder "gobernar a individuos y colectivos por medio de prácticas de corrección, exclusión, normalización, disciplina, terapéuticas y optimización" (Lemke, 2011, p. 5), adquieren una nueva dimensión. Las estrategias de hacer ciudadanos impuestas desde arriba prevalecerán con mayor facilidad frente a la capacidad de producción de proyectos desde abajo (Rose, 2007). La investigación de la biodesigualdad conduce así a la noción de subciudadanía biológica, construida a partir de una reflexión sobre los determinantes sociales de la salud (Sparke, 2017), que afecta de manera problemática al concepto de democracia deliberativa (Arnason, 2017). Frente a las críticas contra las biotecnologías aplicadas al desarrollo de la condición humana (transhumanismo), hay quienes defienden su regulación y control democráticos a fin de lograr la igualdad social y los valores humanos (Shin, 2017), aunque parece incontestable que la globalización, en la contraposición Norte-Sur, podría ser cruel al respecto.

\section{Crisis de representatividad e hiperliderazgo}

La desafección actual de los ciudadanos con la clase política y el sistema de partidos es motivo de preocupación según se contemple el hecho (Tormey, 2015). El peligro de la posdemocracia es convertir la democracia en una cáscara formal, con un sofisticado aparato político y partidista al servicio de los intereses de unas minorías. La crisis de representatividad traduce los efectos perversos de la profesionalización política. Nuevas generaciones de políticos que no han conocido otra actividad que la política, cifran en ella el ansia de reconocimiento y de mejora económica personales, haya o no verdadero talento político. Se enaltecen las habilidades de comunicación política en detrimento del capital intelectual, las competencias funcionales y los comportamientos que expresen inteligencia y compromiso morales.

Esta imagen de degeneración democrática puede sin embargo oponerse a la vitalidad actual de nuevos sujetos políticos y formas de acción colectiva innovadoras, asociadas a la reivindicación de la democracia directa, que reaccionan de manera ambivalente contra la lógica de la democracia representativa liberal. Se rechaza que políticas juzgadas antidemocráticas se justifiquen e implementen en su nombre. Los nuevos ciudadanos antes que votar, actúan. No se afilian a partidos, establecen sus propias redes, asambleas y proyectos. Se alzan contra las políticas de los políticos y el papel de los medios en la esfera 
pública porque ellos mismos son los medios. En la reflexión acerca de la nueva ciudadanía, la invitación metafórica al jazz resulta provocadora y atractiva. Lo que caracteriza al jazz y a la democracia no es una repetición pasiva de las reglas sino su relativización; ni el mantenimiento de identidades provincianas, sino la subjetivación política: "el jazz vincula la improvisación con los materiales tradicionales, la rebelión con el respeto a las reglas básicas, la originalidad y la innovación con tonos e instrumentos ya definidos" (Vodovnik, 2017, p. 10).

El hiperliderazgo como tendencia al alza ilustra de manera paradójica esta crisis de representatividad. Supone un exceso en la manera de entender y ejercer el poder, si bien no es un fenómeno nuevo y quepa diferenciarlo del autoritarismo (Lasalle y Quero, 2019). La política democrática está acusando la irrupción y consolidación de líderes que respetan la estructura básica del estado de derecho, pero se comportan como viejos señores, vueltos sobre sí mismos, incapaces en la práctica de entender un poder condicionado, más preocupados por la expresión personalista del poder que por la construcción democrática del mismo. El líder se autolimita, el hiperlíder -traduciendo una visión casi religiosa del poder- convierte la democracia en un ritual del poder soberano, apela a la lógica de la política directa, estableciendo vínculos inmediatos con la ciudadanía, en su afán de encontrar salidas rápidas a los problemas presentes. Aun erigido en salvador democrático, esa deriva debilita la cultura política democrática en sociedades poco vigilantes. El liderazgo es un valor; el hiperliderazgo, un peligro.

Su relación con el auge de los populismos y la demagogia actuales no puede ser obviada. ¿Es el hiperliderazgo una reacción excepcional de carácter defensivo ante la crisis de representatividad y las nuevas amenazas a la democracia, o más bien los hiperliderazgos se estarían contagiando de un nuevo modelo de hacer política? Lo primero suscita escepticismo en la discusión académica: los nuevos liderazgos son vistos como un síntoma y agravante al mismo tiempo de los problemas que pretenden abordar (Scott, 2018). Atendiendo a lo segundo, "el plus de liderazgo en los hiperlíderes sería pues un acto reflejo, que los aproxima y asemeja a aquellos que pretenden sustituir a su conveniencia la institucionalidad liberal" (Gutiérrez-Rubí y Morillas, 2019, pp. 94-95).

\section{El triunfo del nacional-populismo}

La invocación y la utilización del pueblo tampoco son nuevas, acompaña a todas las ideologías desde finales del siglo XVIII. El triunfo actual del nacional-populismo manifestaría el presunto fracaso de los movimientos sociales de comienzos del siglo XXI ${ }^{5}$. En lugar de más democracia, lo que ha aportado la segunda década es un avance del autoritarismo. Esta paradoja ha puesto de relieve la necesidad de ampliar la perspectiva de estudio sobre los movimientos sociales, atendiendo no solo a los progresistas sino también a los conservadores, así como a los actores y movimientos desde arriba (Pleyers y Álvarez-Benavides, 2019, pp. 145-147). Algunas experiencias recientes parecen dar la razón a Bobbio cuando consideraba que la crítica a la democracia representativa no conduce por sí misma a la democracia directa. Recordaba cómo las asambleas ciudadanas de matriz rousseauniana sólo pueden funcionar en comunidades pequeñas con problemas sencillos. En las sociedades complejas la democracia directa resulta inviable, además de inconveniente por sus rasgos potencialmente antipluralistas, si quisiera hacerse realidad el mito social de la voluntad general. La democracia directa no supone un salto cualitativo respecto a la democracia representativa, por más que pueda complementar a esta, aun siendo complicado convenir los criterios (Bobbio, 1986, pp. 32-42).

5 Sobre la originalidad del nuevo ciclo de protesta y las continuidades y rupturas desde el 68 francés al 15-M español, véase Romanos (2018). 
La apelación a la democracia directa como alternativa al fracaso político de los regímenes democráticos representativos, incapaces de obtener resultados conforme a la voluntad del pueblo, ha sido un argumento habitual de los partidos populistas, especialmente cuando están en la oposición (Jacobs, Akkerman y Zaslove, 2018). Pese a que el populismo se veía a finales de siglo XX como una fuerza en declive (Di Tella, 1997), hoy se ha convertido en una corriente principal de las democracias occidentales, hasta hablarse de un Zeitgeist populista (Mudde, 2004, 2007). El populismo manifiesta una naturaleza camaleónica adoptando posiciones nacionalistas (el pueblo abstracto de los populistas como comunidad imaginada se asemeja a la nación de los nacionalistas) o radicales de izquierda y derecha. Encierra un potencial democrático, no democrático y antidemocrático a la vez en su misma apelación a la refundación del sistema (Riedel, 2017). La razón de su triunfo descansa en que el populismo, más que una ideología, es un relato o incluso un repertorio discursivo y estilístico, cargado de imágenes simples (Brubaker, 2017; Ungureanu y Serrano, 2018).

El relato populista fuerza la imagen de las élites en el poder-esencialmente corruptas y fuente de todos los males sociales y políticos- contrapuesta a la del pueblo puro, heroico y salvador, de donde debe emanar el líder que se pronuncie de manera franca, en nombre de la mayoría, contra las minorías privilegiadas. Es una variante del mito de las dos naciones bien localizado en el lenguaje culto europeo del último cuarto del siglo XIX (la nación sana del subsuelo, sin fisuras, la nación del porvenir, confrontada a una minoría política dominante, corrupta e ineficiente, la nación en el poder). Al lograr una repolitización antagonista de dominios despolitizados de la vida cotidiana, ese discurso se torna eficaz en contextos señalados de crisis como traduce el momento populista actual: millones de votantes consideran que el pasado fue superior al presente y que el futuro empeorará todavía este hoy precario (Eatwell y Goodwin, 2019). No hay proyecto de futuro: se impone un presentismo dramático: el aquí y ahora, el nosotros primero ${ }^{6}$, donde se abre paso la posverdad, llenando la falla creada por la quiebra deliberada de los límites del discurso políticamente correcto.

\section{Los abusos de la posverdad}

La manipulación, la propaganda y la desinformación son viejas prácticas. Lo que es nuevo son los medios, el alcance y las consecuencias del fenómeno: la capacidad de fabricar -no ya un mito, una mentira, una ficción- sino una nueva voluntad general al margen del contrato social, lo que resulta problemático en democracia. La negación de la verdad, el desprecio a los hechos y a la opinión pública se han convertido en práctica política corriente; los ciudadanos no están en condiciones de distinguir la verdad de la falsedad; o ni siquiera de saber cuándo se manipulan los procesos democráticos. Se ha naturalizado en democracia la máxima de Goebbels -una mentira repetida mil veces se convierte en verdad-, y existe además la percepción de que ya no cabe acceder a ella. El auge de lo virtual habría aniquilado y sustituido a lo real, por lo que la búsqueda de la verdad se torna imposible y la mentira pierde todo significado. No hay manera de controlar y verificar lo que se dice en el marco actual de "digitalización de la democracia" (Schapals, Bruns y McNair, 2019).

Cuando se relativiza la posverdad con ejemplos del pasado como la propaganda nazi o soviética se erosiona la democracia, pues se prescinde del hecho principal: la defendible superioridad moral de la democracia, que apunta a la verdad como virtud cívica. Sin verdad, sin ser capaces de reconocer la realidad exterior al lenguaje, sin hacer justicia a la experiencia vivida, no se puede llegar a acuerdos de consenso. Lo que ahora se llama

6 Cabe contraponer entonces este aqui y ahora propio de un sentir de la población en la experiencia de la crisis al aqui y ahora como inicio del cambio social a través de la praxis cotidiana y la acción simbólica, según lo entienden los activistas de los movimientos sociales pos2010, subestimando la fuerza del primero en el imaginario colectivo. 
la batalla del relato es realmente otra cosa. La concurrencia de hiperlíderes o de líderes populistas agrava el problema. Compiten entre ellos por la burda simplificación de los problemas sociales y políticos, por la articulación de discursos binarios, sin brillo ni contraste alguno, afirmados con toda rotundidad, exigiendo adhesión plena y la estigmatización del diferente. Desacreditan la palabra pública por su falsedad y autoritarismo de fondo.

La deriva de los medios de comunicación -luchando por la supervivencia en la ambigüedad y cacofonía de internet y las redes sociales- no ayuda. La información contrastada se refugia en plataformas de pago, abandonando a su suerte en la selva mediática a la opinión común, cada vez más fragmentada. La propia arquitectura de las redes sociales facilita la multiplicación de burbujas aisladas de información, al arbitrio del consumidor, y la consiguiente polarización de los grupos de referencia donde se reafirman o exacerban las creencias o actitudes de origen. Esta dinámica limita la exposición a información inesperada, no direccionada previamente, lo cual afecta al normal funcionamiento de la democracia. La idea de una esfera pública, sostenida en el pensamiento crítico y la cultura de la libertad, que responda a un amplio espacio de experiencias compartidas por los ciudadanos, comienza a ser problemática (Hopia, 2013; Sunstein, 2017, 2018).

La entronización de la posverdad en la era virtual de la comunicación es una amenaza para la democracia. Una sociedad no puede sobrevivir instalada en la mentira institucionalizada. La democracia no es un simple sistema procedimental, requiere la búsqueda de la verdad o veracidad, aun sabiendo que la verdad está muy repartida en política. La acción de la demagogia y del líder mentiroso altera la sustancia misma de las relaciones humanas, fundadas en la confianza en la palabra del otro. No es indiferente saber si se están propagando mentiras deliberadamente, o si se está forzando desde dentro o desde fuera la voluntad política de la ciudadanía. Estamos ya experimentando los riesgos del "mundo insufrible al que daría pie la era de la posverdad: ya no sabríamos a qué atenernos con relación a la palabra en el espacio público" (Valadier, 2017, p. 303). La posverdad no es una acción creativa sino un abuso que renuncia a la reflexividad democrática para transformar la realidad.

\section{El doble filo de la performatividad}

El problema de la verdad se diluye en el marco performativo de la democracia actual, donde lo que importa no es lo verdadero o lo falso sino el éxito o fracaso de la representación (Alexander, 2017; Sánchez-Prieto, 2013). Los nuevos movimientos sociales hicieron valer a través de la acción simbólica el poder de la representación afrontado a la representación del poder con voluntad de profundizar en la cultura democrática ${ }^{7}$. Filo mordiente que ha reforzado, por reacción, la teatralidad de la política institucional. Asistimos al progreso de la política esteticista, la escena convertida en espacio sacro ${ }^{8}$ : el culto por el ritual, la liturgia, los gestos de naturaleza simbólica, el espectáculo teatral como objetos políticos centrales y medios fundamentales para el reencantamiento de voluntades o la anulación de contrarios. Se registra igualmente un estallido de la emocionalidad política, la pasión alzada contra la razón política, no ya como signo distintivo de la protesta social (Goodwin, Jasper y Polletta, 2001), sino como marca personal del hiperlíder que busca interaccionar con la ciudadanía desde una imagen de cercanía y autenticidad (Lasalle y Quero, 2019, pp. 10-12). Esta emocionalidad desbocada exacerba las emociones adversativas en pro de la ruptura mientras orilla las emociones políticas más cercanas al ethos democrático y a la construcción del hombre político como puedan ser la tolerancia, la apertura al diálogo o la resistencia al fracaso (Arias Maldonado, 2016; Wirz, 2018).

7 El análisis de esta dinámica es primordial para la nueva sociología cultural (Côté, 2019).

8 El caso de Macron es paradigmático (Bourekb y Hahn, 2019). 
Las redes sociales en cuanto tecnologías intrínsecamente afectivas han permitido reducir la distancia entre gobernantes y gobernados, pero la deriva de una política directa, consustancial al hiperliderazgo y al populismo, sin verdaderos anclajes institucionales ni intermediarios reconocibles, conduce a la "progresiva sustitución de la institución por la emoción" (Gutiérrez Rubí y Morillas, 2019, p. 95), algo embarazoso en democracia. Si la tecnología consiguiera además acceder al corazón humano (Gibilisco et al., 2018; Weitzel, 2019) y los políticos pulsar nuestros resortes emocionales generando ansiedad, ira, resentimiento, alegría o aburrimiento a su antojo, la política se convertirá pronto no ya en un teatro sino en un "circo emocional" (Harari, 2018, p. 103). La razón política debe aprender a dialogar con los afectos y emociones de manera provechosa para el debate democrático y la negociación estratégica de las relaciones de poder (Martin, 2013; Heaney, 2019), pero la democracia bajo capa de creatividad no puede entregarse o verse reducida al puro espectáculo performativo.

\section{La soberanía del algoritmo}

Entretenidos los políticos con sus juegos performativos, la autoridad puede cambiar pronto de titular. ¿Hablarán los futuros tratados de ciencia política de la soberanía del algoritmo, del trasvase de la soberanía de Dios al soberano, del soberano al pueblo y de este al algoritmo? Si la democracia extiende el poder y las formas de procesamiento y acceso a la información para la toma de decisiones, la IA trabaja en sentido contrario y permite concentrar y manejar con inmediatez volúmenes ingentes de datos. Trasladar la toma de decisiones al algoritmo supondría el repudio de la política y el advenimiento de dictaduras digitales con ropaje democrático. La democracia algorítmica basada en el dataísmo y la política de datos socava la autonomía humana. El problema no es tanto dejar que los datos tomen cada vez más decisiones por nosotros mismos, como que acaben ejerciendo la autoridad sobre nuestras vidas (Son, 2019). Las nuevas experiencias chinas de vigilancia ciudadana automatizada (el Sistema de Crédito Social basado en sofisticados y complejos algoritmos) merecen atención (Kshetri, 2020). El concepto de sujeto postsoberano (introducido por Muñoz Maldonado para señalar los límites del sujeto hiperracional y su múltiple exposición a los afectos y emociones) alcanzaría ahora un nuevo sentido.

El giro algorítmico ha mostrado la efectividad de los big data -la mano invisible de la tecnología- para promocionar a un político, manipular la opinión pública o distorsionar los procesos electorales, poniendo en jaque la realidad de una esfera pública (Gurumurthy y Bharthur, 2018). El escándalo de Cambridge Analytica (2018) ha revelado la utilización por terceros de los datos y perfiles de Facebook para fabricar victorias tan decisivas como la del referéndum del Brexit o las presidenciales de Trump. Ello ha generado diversos debates (Hernández H., 2020). Primero sobre la problemática del perfilado ideológico realizado a través de técnicas de big data (fueron procesados perfiles conductuales y psicográficos completándose la información obtenida en redes sociales con cuestionarios a usuarios cumplimentados mediante pago) para depurar audiencias y enviar mensajes personalizados, si no noticias falsas sobre temas sensibles segmentados en función de los destinatarios. En segundo lugar, sobre la vulneración del derecho a la protección de datos, fuera de otras consideraciones sobre el negocio e intermediación en un mercado de datos falto de regulación (el control de los datos queda en manos de la autorregulación de las empresas dominantes del sector, que tienden a violar el insuficiente marco protector global de la privacidad).

Los datos son hoy los bienes mas preciados, como antaño la tierra o los medios de producción. ¿Se ha convertido el poder de la información en un nuevo poder incontrolado? ¿Pero se puede controlar sin atentar contra la democracia? ¿A quien pertenecen los datos? 
¿Cómo se puede regular su propiedad? No es fácil separar los sistemas de datos públicos de los grandes capitalistas de datos, dada la reconfiguración de la infraestructura pública en enclaves privados, lo que sienta preocupación por el bien público y la responsabilidad ciudadana. Más preguntas difíciles: ¿Puede encontrarse un equilibrio entre la privacidad individual de los datos personales y su consideración como un bien colectivo de valor público? ¿Deben someterse los datos y la IA a supervisión pública para garantizar el proyecto democrático y los derechos ciudadanos, o es preciso más bien salvaguardar el control de los datos en manos de la sociedad civil para evitar que el poder del algoritmo transforme los gobiernos democráticos en dictaduras digitales? Si la amenaza del también llamado "colonialismo digital" (Ávila, 2018) pesa sobre las democracias, todavía inquietan más las desviaciones de la soberanía del algoritmo en los regímenes autoritarios. Sin transparencia y sin un plan claro para abordar sus defectos y carencias, el "fetichismo del algoritmo" (Monahan, 2018) puede traer más daños que bienes.

\section{DISCUSIÓN: HACIA UNA DEMOCRACIA CONSCIENTE Y RESILIENTE}

\section{Conciencia, participación y otras virtudes cívicas}

En el reverso de este debate subyacen algunas propuestas que apunto de manera reflexiva, pues permiten aflorar algunos vínculos conceptuales entre democracia y creatividad. El ideal democrático apela a la conciencia. La ciencia actual sabe mucho del cerebro, menos de la mente y poco de la conciencia. Afortunadamente los algoritmos no tienen conciencia y el uso de la IA continuará supeditado a la conciencia humana, fondo cognitivo donde se integran y refiguran conocimientos, valores y experiencias en una dinámica que es tanto individual como social, según ha insistido Norbert Elias (2016, pp. 141, 221-226). El mito del algoritmo ha creado una meta-narrativa de tecno-modernidad que todas las sociedades deben acoger como ideal de progreso, pero que obvia la conciencia como centro germinal de la misma vida colectiva. La expansión de la tecnología y la integración de la IA en nuestras sociedades debe someterse a la rendición de cuentas, pues es la intención humana en última instancia la que determina el sentido democrático o no de los usos y aplicaciones de cualquier tecnología. Son necesarias políticas que afronten eficazmente fenómenos como la vigilancia, la desinformación y la ingeniería social para garantizar la libertad, el espíritu de deliberación y el compromiso político en un tecnopaisaje abrasivo para la propia obligación de discernimiento.

La conciencia es inseparable de la libertad. En el actuar en conciencia radica el verdadero drama de la toma de decisiones, como reconocía Hitler al querer liberar a la humanidad de una carga que pocos hombres eran capaces de soportar: la conciencia. Históricamente pudo creerse que era más fácil obedecer o, más adelante, diluirse en el gregarismo de la muchedumbre solitaria (Riesman, 1950), fenómeno que revive hoy en un mar de datos y dispositivos cada vez más sofisticados y eficientes. Promover el desarrollo de la conciencia humana como requisito para el renacimiento democrático conduce hacia democracias más éticas, no solo para combatir la desmoralización de la que hablaba Ortega y Gasset (1947, pp. 72-73). El rearme ético refuerza el sentido de la libertad y la creatividad. La libertad es afirmación y autolimitación conscientes. ¿Debe esto aplicarse igualmente al progreso indefinido de la ciencia y la tecnología? La ética de la tecnología se abre a la discusión de las virtudes tecnomorales que incumben a las redes sociales, los métodos de vigilancia, la robótica o las tecnologías de perfeccionamiento humano (Vallor, 2016). ¿Cuáles son las líneas rojas que no se pueden/deben traspasar? ¿Deben someterse al escrutinio moral público y a los métodos de la democracia deliberativa (Kim, Wall, Stanczyk y De Vries, 2009; Howard, 2018)? 
¿Debe ser la reflexividad una condición de los líderes y gobiernos democráticos? La fijación en el aquí y ahora impide reflexionar y decidir en conciencia. Favorece, por el contrario, el cortoplacismo (inducido por el propio ciclo electoral, la mirada atenta al último tuit o encuesta publicada) y la tentación de los dictadores benévolos que actúan con visión a largo plazo (ese es el éxito de China que ha sido contestado por los estudiantes de Hong-Kong). El verdadero líder piensa en términos de totalidad, atiende al conjunto de la sociedad y al objeto del Estado democrático, pero no ignora que la evolución creativa de la sociedad descansa en la responsabilidad individual. Una política creativa favorece el pensamiento integrador, a nivel individual y colectivo, una mentalidad de posibilidad para explorar el espacio liminar entre las propias diferencias de tal forma que la diversidad y lo que separa no se presente interesadamente como fuente inevitable de conflictos, sino como oportunidades de aprendizaje y de innovación, superando los juegos de suma cero. La democracia une a través de las diferencias (ideológicas, emocionales, políticas) y reclama de todos -gobernantes y ciudadanía-intención y propósito.

La participación, antes que fórmulas imaginativas y poco viables a menudo, requiere conciencia y voluntad. Una voluntad consciente, por parte del ciudadano, para conjugar sus derechos, valores y responsabilidades, siendo también capaz de involucrarse y aprender de las intenciones, valores y propósitos de otros que son diferentes o piensan diferente. La democracia directa no es tanto una ingeniería para lograr la expresión de una voluntad social, como el despertar de actitudes y comportamientos que generen dicha voluntad social: vivir una vida democrática de ideas y experiencias, co-creando y extendiendo un poder compartido que beneficie a todos, en lugar de ejercerlo sobre otros en provecho propio inmediato (Follet, 1998). Esta dimensión es particularmente relevante en la nueva comprensión y análisis de los movimientos sociales y de su papel en la transformación de la democracia. Participación, conciencia y responsabilidad van de la mano. La responsabilidad de liderar, contribuyendo a la solución de los problemas comunes, compete a cada ciudadano, aunque pueda resultar más fácil confiarla a la autoridad y poder del gobernante, del experto o del algoritmo. Dirigir y responder, vivir la democracia, apela siempre a un líder consciente y moral que consulta y sigue al líder silencioso interior de la intención y el propósito. Es atendiendo a ese ser comprometido y consciente, que es un ser moral, cómo la sociedad civil (y no el pueblo abstracto) se vuelve un proceso creativo -emergente, ascendente, participativo, emprendedor y dinámico-donde la democracia directa aparece como el reverso necesario de la democracia representativa, antes que como un contrapoder o contrademocracia que exacerba la distinción entre nosotros y ellos, según tiende a concebirse o ejercitarse hoy (Rosanvallon, 2007).

El viejo ideal de una ciudadanía activa y virtuosa, que el jacobinismo no supo administrar, mantiene su validez democrática, aunque se insista más hoy en la participación que en las virtudes cívicas. La primera y fundamento de las demás virtudes es la alineación de las prácticas con los ideales profesados por la comunidad, una exigencia de coherencia consustancial a los movimientos sociales y siempre viva. Las virtudes cívicas pueden variar de una comunidad a otra al igual que se distinguen en su seno diferentes creencias, esferas de actividad y roles que asisten al bien común, pero ello no significa que no haya virtudes cívicas comunes a todas las sociedades (Galston, 2007). ¿Cuáles? Las clásicas (Pérez-Díaz, 2006): la autonomía (el cuidado por la libertad de uno), la amistad (relativa a la libertad del otro próximo) y la piedad (la atención a la libertad del otro lejano). Esta última se extiende no sólo en el espacio geográfico o cultural (el extraño, el inmigrante, el extranjero) sino también en el tiempo, implicando a las generaciones pasadas (el respeto a la memoria y obra de los antecesores) y a las generaciones futuras (privadas hoy de sus derechos

9 Un informe de la BBC (Krznaric, 2019) recoge algunos planteamientos radicales derivados de la critica a las asambleas ciudadanas que no llegan a alterar la estructura de la democracia, como el del activista canadiense David Zuzuki, partidario de reemplazar los políticos electos por una asamblea de ciudadanos seleccionados al azar, como los jurados populares a nivel judicial, y con un mandato de 6 años, convencido de que serían capaces de acometer con más eficacia los problemas a largo plazo. 
como antaño lo estuvieron los esclavos o las mujeres). La preocupación por la suerte de los sucesores ${ }^{10}$ está unida a la propia necesidad de implicar a la juventud en defensa de la democracia como lo está en la causa del planeta.

\section{El poder creativo de la resiliencia}

La ética del cuidado se presenta como un firme compromiso cívico frente a las amenazas que sufre la democracia (Stone, 2019). La democracia consciente requiere a su vez un capitalismo consciente (Mackey y Sisodia, 2013), con una visión más amplia y un propósito superior, capaz de trascender el dogma neoliberal para transformarse e implicarse en la construcción de un futuro más cooperativo, humano y esperanzador. La búsqueda de lo humano supone un ejercicio continuo de empatía y cultivo de las emociones que llevan a comprender los afanes y temores de los demás (Nussbaum, 2005). Es la premisa para extender el concepto de resiliencia a la política democrática. La resiliencia entendida no sólo como la capacidad de resistir, absorber las perturbaciones y recuperarse de un acontecimiento o proceso adverso. No es un concepto puramente estratégico dirigido a restablecer el equilibrio, previendo los riesgos y anticipando desde la experiencia vivida las respuestas a situaciones de vulnerabilidad o cualquier tipo de desastre (Frerks, Warner y Weijs, 2011). Lo que importa realmente no es hacer frente a la adversidad, ni siquiera superarla, sino la transformación positiva del propio sujeto, sistema o sociedad ante el infortunio, rehacerse verdaderamente.

La resiliencia exige un cambio de mirada para acoger y hacer propia la desdicha de otros. Se requiere la virtud de la compasión, algo más que solidaridad, para comprender con profundidad el dolor y sufrimiento humano, si quiere reducirse como imperativo moral. La política de la compasión difiere de la política meritocrática y distingue con claridad el mundo de la representación y el de la acción. El sufrimiento nunca es virtual, aunque sea contemplado desde la distancia o la pantalla, y a diferencia de la lástima la compasión siempre es práctica, se implica para actuar sobre determinadas realidades, apela a gobiernos y ciudadanos, y debe movilizar a la opinión pública en ese compromiso de participación (Boltanski, 2007). La preocupación resiliente por el presente es el modo afectivo/efectivo de crear el futuro que se nos escapa. La resiliencia como fuerza creativa, lejos de consagrar estructuras o equilibrios del pasado, invita a reconstruir mejor. Como proceso interactivo individuo-sociedad constituye un poderoso instrumento de desarrollo e innovación, de transformación social. Todas las sociedades democráticas han de transformarse y rehacerse de nuevo, cobrando nuevo impulso, en la conciencia y experiencia de la adversidad.

La crisis del COVID-19 ha sido un acontecimiento inesperado que afronta brutalmente a ello. Originada en China, Europa y EE. UU. se convirtieron enseguida en epicentro de la pandemia y del desastre ocasionado por el virus. La primera reacción fue de incredulidad, miedo social y pánico económico ante el colapso inminente, cuando se creía superada la crisis de 2008. El regreso a la realidad sorprendió a algunos gobiernos, que no supieron adoptar medidas preventivas a tiempo y mostraron su ineficacia en plena gestión de la emergencia. En su declaración de guerra al enemigo invisible los hiperlíderes no resistieron a la tentación de la propaganda y la unilateralidad, buscando el cierre de filas en torno a ellos. Los más nacional-populistas hablan del virus invasor que nos mata. Pero la fuerza de los hechos permitió celebrar el retorno a la esfera pública del conocimiento cualificado

\footnotetext{
10 Algunos países han ensayado fórmulas para atender a las generaciones futuras, como la Comisión del Futuro en Finlandia, encargada de elevar al Parlamento un Informe sobre el Futuro del País en cada legislatura y de velar por el fortalecimiento de la democracia, con réplicas en Brasil o México. Israel, Hungría, Gales y Alemania han impulsado a su vez Defensores, Comisionados o Fundaciones de las Generaciones Futuras, y en el Reino Unido se ha llegado a proponer la creación de una Tercera Cámara de los Guardianes del Futuro.
} 
frente a la posverdad fútil. Y en la experiencia vivida, hacerse cargo de la realidad de tantas personas de otros continentes que sufren confinamientos, cierre de fronteras, falta de recursos sanitarios y viven en la incertidumbre o conviviendo con la muerte indiscriminada de manera habitual. El virus invisible ha hecho ver realidades invisibles.

El virus ha forzado el encierro, pero a diferencia de la antigua peste esta distancia social ha creado un nuevo sentimiento colectivo de comunidad y fraternidad. Nadie se salva si se salva solo. La resiliencia social se ha manifestado más fuerte que la política, emplazada a situar la vida de los individuos por delante de la economía sin convertir el escudo social en argumento de lucha ideológica. Los políticos han sido poco sensibles al dolor de quienes no pudieron acompañar en la muerte a sus mayores. Las democracias, mirando a los antiguos, necesitan aprender a llorar mejor (Stow, 2017). La crisis del COVID-19 coloca a las democracias en una encrucijada donde su lectura de la resiliencia será decisiva. La primera elección supone una visión corta de la resiliencia, ligada a las ideas de resistencia y refuerzo de la vigilancia para adelantarse a la amenaza/adversidad, vencerla y preservar a la sociedad y el Estado (Coaffee y Rogers, 2008; Jones, Raab y Szekely, 2018), una concepción que habría salido reforzada de la crisis ante el aparente éxito de las técnicas de biovigilancia y big data aplicadas en algunos países asiáticos. Esta opción, aun salvando la voluntad de autolimitación del Estado, afianza las dictaduras digitales. La segunda es más ambiciosa e implica un cambio de valores y un rearme ético, no sólo para encarar con valentía el futuro, sino para edificarlo sobre bases auténticamente humanas.

La resiliencia -reconfigurando el nudo de relaciones entre emociones y políticapuede alumbrar una democracia afectiva y compasiva que haga prevalecer la capacidad de entendimiento sobre la dinámica de mutuas exclusiones, las batallas de la identidad o el nuevo culto a la frontera, forzando a los políticos a asumir sus verdaderas responsabilidades: a) el mantenimiento del orden de libertad, sabiéndolo adaptar a las circunstancias cambiantes (siempre desde el respeto a las instituciones democráticas y la cultura de la libertad); y b) la preocupación efectiva por el bien común y bienestar de todos, que conlleva ciertamente la mejora de la dura situación presente. El poder del algoritmo no nos vuelve inmunes, ni reduce la vulnerabilidad a cero. La resiliencia realmente tampoco, pero al hacernos conscientes de nuestros límites nos hace más humanos y consiguientemente más capaces de superarlos para lograr la transformación personal y social. La resiliencia puede impulsar asimismo una transformación política. La virulencia del COVID-19 como problema global ha fortalecido la conciencia de comunidad global y hecho evidente al tiempo la utopía de un gobierno global. Pero ante las ineficacias en la respuesta a la crisis, no es ingenuo el planteamiento de globalizar la política. Desde el reconocimiento de democracias múltiples, quizá sea necesario para revertir el deterioro de la democracia en el mundo y las nuevas tentaciones de estatalismo.

\section{Los derechos humanos como moral colectiva}

Hoy más que nunca, reciente su 30 aniversario, puede afirmarse que los derechos humanos no están obsoletos, aunque algunos los consideren un dogma laico inhabilitado para "tratar con superhumanos, ciborgs y ordenadores superinteligentes" (Harari, 2018, p. 236). Su permanente actualidad deriva de su dimensión de moral o conciencia colectiva. El papel ético-político de los Derechos Humanos, consagrado en el preámbulo de su Declaración -alma del originario Estado resiliente de bienestar europeo-, es obviado en la práctica o por la crítica cuando se reducen los derechos humanos a "la ideología del intervencionismo militar que sirve a propósitos específicamente económico-políticos" (Zizek, 2005, p. 194) o se sostiene que la "la ética es solamente un discurso de propaganda" (Badiou, 2007). Desde la teoría política se ha prescindido de la vertiente moral de los 
derechos humanos en favor de sus regulaciones prácticas en el ámbito internacional, aunque estas dependan en última instancia de algún tipo de llamamiento a los derechos humanos morales (los que se poseen en virtud de la simple humanidad), como ha hecho notar Renzo sosteniendo en este debate la prioridad de la moral, sin atender a la cual difícilmente puede explicarse el vínculo entre los derechos humanos y la salvaguardia de la dignidad humana, consustancial a su propósito (Renzo, 2015, p. 143). Conciencia y resiliencia, una vez más, como bases de la respuesta creativa que ha de dar la democracia en el actual escenario de crisis y cambio.

\section{CONCLUSIÓN}

La creatividad ha de mejorar las respuestas económicas, sociales y políticas a la realidad presente, tan incierta en un tiempo marcado por dos grandes crisis como son la iniciada en 2008 y la inmediata del COVID-19. El desafío es reinventar la democracia misma. No se trata sólo de superar su cortoplacismo y abordar el robo intergeneracional del futuro ${ }^{11}$. Como todo proceso creativo, exige un trabajo de mezcla y reciclado, de depuración y recreación, un proceso siempre activo y de resultado abierto. Que una democracia sea considerada creativa depende de la aceptación final de su novedad. Pero es la fuerza de la creatividad la que empuja desde el inicio a plantear nuevas cuestiones o tratar de solucionar de manera novedosa los viejos problemas. La encrucijada actual del estado de bienestar; la crisis de la democracia representativa y las nuevas demandas de democracia directa; o las amenazas de las tecnologías disruptivas en términos de pérdida de la ciudadanía laboral, biodesigualdad o desarrollo de dictaduras digitales son fenómenos acuciantes que apelan, en su necesidad de respuesta, a esas capacidades de búsqueda, de interiorización, de contemplación y reflexión crítica propias del talento creativo.

La política y el estado contemporáneos se han transformado históricamente asumiendo nuevos papeles y responsabilidades al ritmo de las propias transformaciones económicas y sociales. Urgen soluciones creativas frente a las políticas de repliegue, defendidas hoy por el nacional-populismo, cuando hay nuevos retos y problemas a los que la democracia queda afrontada y fuerzan su propia transformación. La crisis del coronavirus no ha venido sino a confirmarlo poniendo de manifiesto a la hora de la verdad algunas debilidades y querencias de las democracias actuales. La performatividad social ha replanteado las bases de las prácticas comunicativas y del ejercicio del poder, aunque sus muestras de creatividad han asentado nuevas formas de propaganda al servicio de los intereses y pasiones políticas inmediatas. La discusión sobre la reinvención de la democracia conduce finalmente hacia una conciencia creativa y la resiliencia como claves del fortalecimiento de la cultura democrática, así como de la presente exigencia de reconstruir mejor. El nuevo horizonte de una democracia consciente y resiliente revela que la resiliencia no es sólo motor de creatividad sino uno de sus principales resultados.

\section{REFERENCIAS}

Abramowitz, M. J. (2017). Freedom in the World 2018. Democracy in Crisis. Recuperado de https://freedomhouse.org/report/freedom-world/freedom-world-2018

Albert, M. (1991). Capitalisme contre capitalisme. París: Seuil.

Alexander, J. (2017). Poder y performance. Madrid: CIS.

11 Según considera el informe Krznaric (2019). 
Alonso, L. E. (2007). La crisis de la ciudadanía laboral. Barcelona: Anthropos.

Arias Maldonado, M. (2016). La democracia sentimental. Política y emociones en el siglo XXI. Barcelona: Página Indómita.

Arnason, V. (2017). Biological or Democratic Citizenship. En P. Kakuk (ed.), Bioethics and Biopolitics: Theories, Applications and Connections (pp. 31-45). Nueva York: Springer.

Ávila, R. (2018). Digital Sovereignty or Digital Colonialism? SUR International Journal on Human Rights, 27, 15-27.

Badiou, A. (2007). Reflexiones sobre nuestro tiempo. Buenos Aires: Del Cifrado.

Bobbio, N. (1986). El futuro de la democracia. México: FCE.

Bodei, R. (2007). ¿Hacia humanos de criadero? Themata, 39, 15-22.

Bogomiagkova, E., Orekh, E. y Lomonosova, M. (2016). New Configurations of Social Inequality in the context of Biotechnologies Development. En Psychology and Psychiatry, Sociology and Healthcare (Vol. II) (pp. 667 y 674). Albena: SGEM. https://doi.org/10.5593/ SGEMSOCIAL2016/B12/S02.086

Boltanski. L. (2007). La souffrance à distance. Morale humanitaire, médias et politique. París: Gallimard.

Bourekb, M. y Hahn, A. (2019). Enmanuel Macron: ¿rey sin corona? En A. Gutiérrez-Rubí y P. Morillas (coords.), Hiperliderazgos (pp. 15-24). Barcelona: CIDOB.

Brubaker, R.(2017). Why populism? Theory and Society, 46(5), 357-385. https://doi.org/10.1007/ s11186-017-9301-7

Coaffee, J. y Rogers, P. (2008). Rebordering the City for New Security Challenges: From Counter Terrorism to Community Resilience. Space and Polity, 12(1), 101-118. https://doi.org/10.1080/13562570801969556

Côté, J.-F. (2019). Jeffrey C. Alexander on the Theatricality of Social Life: Deepening the Hermeneutics of Cultural Sociology. Sociologia \& Antropologia, 9(1), 55-84. https://doi.org/10.1590/2238-38752019v913

Crouch, C. (2004). Posdemocracia. Madrid: Taurus.

Di Tella, T. (1997). Populism into the twenty-first century. Government and Opposition, 32(2), 187-200. https://doi.org/10.1111/j.1477-7053.1997.tb00157.x

Eatwell, R. y Goodwin, M. (2019). Nacionalpopulismo: por qué está triunfando y de qué forma es un reto para la democracia. Barcelona: Península.

Elias, N. (2016). La dynamique sociale de la conscience. Sociologie de la connaissance et des sciences. Paris: La Découverte.

Feenstra, R. (2016). El potencial transformador de la democracia monitorizada a debate: contextualización teórica y diálogo con John Keane. Revista Teknokultura, 13(2), 639654. https://doi.org/10.5209/rev_TEKN.2016.v13.n2.52437

Feenstra, R., Tormey, S., Casero, A. y Keane, J. (2016). La reconfiguración de la democracia: el laboratorio político español. Granada: Comares.

Follett, M. P. (1998). The new state: Group organization the solution of popular government. University Park, PA: Penn State UP.

Freedom House. (2012). Freedom in the World 2010. Essay: Erosion of Freedom Intensifies. Recuperado de https://freedomhouse.org/report/freedom-world/freedom-world-2010 
Freedom House. (2018). Freedom in the World 2019. Democracy in Retreat. Recuperado de https://freedomhouse.org/report/freedom-world/freedom-world-2019

Frerks, G., Warner, J. y Weijs, B. (2011). The politics of vulnerability and resilience. Ambiente \& Sociedade, 14, 105-122. https://doi.org/10.1590/S1414-753X2011000200008

Fukuyama, F. (1989). The End of History? The National Interest, 16, 3-18.

Fukuyama, F. (1992). El fin de la historia y el último hombre. Barcelona: Planeta.

Galston, W. (2007). Pluralism and Civic Virtue. Social Theory and Practice, 33, 625-635.

Gascón, D. (2018). El golpe posmoderno: 15 lecciones para el futuro de la democracia. Madrid: Debate.

Gibilisco, H., Laubenberger, M., Spiridonov, V., Belga, J., Hallstrom, J., Peluso, P. R. (2018). A Multi-Modal Approach to Sensing Human Emotion. 2018 IEEE International Conference on Big Data, pp. 2499-2502. https://doi.org/10.1109/BigData.2018.8622451

Goldfarb, J. (2001). 1989 and the creativity of the political. Social Research, 68(4), 993-1010.

Goodwin, J., Jasper, J. y Polletta, F. (eds.), (2001). Passionate Politics: Emotions and Social Movements. Chicago: The Chicago UP.

Gurumurthy, A. y Bharthur, D. (2018). Democracy and the Algorithmic Turn. SUR International Journal on Human Rights, 27, 39-50.

Gutiérrez-Rubí, A. y Morillas, P. (coords.), (2019). Hiperliderazgos. Barcelona: CIDOB.

Harari, Y. N. (2018). 21 lecciones para el siglo XXI. Barcelona: Debate.

Heaney, J. (2019). Emotion as power: capital and strategy in the field of politics. Journal of Political Power, 12, 224-244. https://doi.org/10.1080/2158379X.2019.1618485

Hernández H., J. C. (2020). Campañas electorales, Big Data y perfilado ideológico. Aproximación a su problemática desde el derecho fundamental a la protección de datos. Manuscrito presentado para su publicación.

Hopia, H. (2013). Decline of the media? Decline of democracy? European View, 12(1), 41-49. https://doi.org/10.1007/s12290-013-0247-5

Howard, D. (2018). Technomoral Civic Virtues: A Critical Appreciation of Shannon Vallor's Technology and the Virtues. Philosophy \& Technology, 31, 293-304. https://doi. org/10.1007/s13347-017-0283-1

Huntington, S. P. (1993). The Clash of Civilizations? Foreign Affairs, 72(3), 22-49.

Huntington, S. P. (1996). The Clash of Civilizations and the Remaking of World Order. Nueva York: Simon \& Schuster.

Innerarity, D. (2019). Una teoría de la democracia compleja: Gobernar en el siglo XXI. Barcelona: Galaxia Gutenberg.

Jacobs, K., Akkerman, A. y Zaslove, A. (2018). The voice of populist people? Referendum preferences, practices and populist attitudes. Acta Politica, 53(4), 517-541. https://doi. org/10.1057/s41269-018-0105-1

Jones, R., Raab, C. y Szekely, I. (2018). Surveillance and resilience: Relationships, dynamics, and consequences. Democracy \& Security, 14, 238-275. https://doi.org/10.1080/17419166 .2017.1423472

Keane, J. (2013). Democracy and Media Decadence. Cambridge: Cambridge UP. 
Keane, J. (2018 [2009]). Vida y muerte de la democracia. México: FCE.

Kim, S., Wall, I., Stanczyk, A. y De Vries, R. (2009). Assessing the Public's Views in Research Ethics Controversies: Deliberative Democracy and Bioethics as Natural Allies. Journal of Empirical Research on Human Research Ethics, 4, 3-16. https://doi.org/10.1525/ jer.2009.4.4.3

Kim, Y. (2019). Al, Employment, Economic Growth, and Inequality: Recent Literature Survey and Policy Implications. The Korean Economic Forum, 12(3), 1-34.

Krznaric, R. (7 de abril de 2019). Por qué necesitamos reinventar la democracia. BBC. Recuperado de https://www.bbc.com/mundo/vert-fut-47802956

Kshetri, N. (2020). China's Social Credit System: Data, Algorithms and Implications. IT Professional, 22(2), 14-18. https://doi.org/10.1109/MITP.2019.2935662

Lasalle, J. M. y Quero, J. (2019). Hiperliderazo: ¿de qué estamos hablando? En A. GutiérrezRubí y P. Morillas (coords.), Hiperliderazgos (pp. 7-13). Barcelona: CIDOB.

Lemke, T. (2011). Biopolitics. An advanced Introduction. Nueva York: New York UP.

Mackey, J. y Sisodia, R. (2013). Conscious capitalism. Boston, MA: Harvard Business School.

Martin, J. (2013). A feeling for democracy? Rhetoric, power and the emotions. Journal of Political Power, 6(3), 461-476. https://doi.org/10.1080/2158379X.2013.846557

Monahan, T. (2018). Algorithmic Fetishism. Surveillance \& Society, 16(1), 1-5. https://doi. org/10.24908/ss.v16i1.10827

Monedero, J. C. (2012). ¿Posdemocracia? Frente al pesimismo de la nostalgia, el optimismo de la desobediencia. Nueva Sociedad, 240, 69-86.

Mouffe, C. (2003). La paradoja democrática: el peligro del consenso en la política contemporánea. Barcelona: Gedisa.

Mouffe, C. (2010). Política agonística en un mundo multipolar. Documentos CIDOB, serie Dinámicas Interculturales, 15.

Mouffe, C. (2014). Agonística. Pensar el mundo políticamente. Buenos Aires: FCE.

Mudde, C. (2004), The populist zeitgeist. Government and Opposition, 39(4), 541-563. https://doi.org/10.1111/j.1477-7053.2004.00135.x

Mudde, C. (2007). Populist Radical Right Parties in Europe. Cambridge: Cambridge UP.

Nelson, G. (2017). Mary Parker Follett. Creativity and Democracy. Human Service Organizations Management Leadership \& Governance, 41(2), 178-185. https://doi.org/10. 1080/23303131.2016.1263073

Niewiadomski, R. y Anderson, D. (2017). The Rise of Artificial Intelligence: Its Impact on Labor Market and Beyond. En R. Batko y A. Szopa (eds.), Strategic Imperatives and Core Competencies in the Era of Robotics and Artificial Intelligence (pp. 29-49). Hershey, PA: IGI Global.

Nussbaum, M. (2005). El cultivo de la humanidad. Barcelona: Paidós.

Olalla, P. (septiembre, 2017). El viejo futuro de la democracia. CTXT. Contexto y acción, 134.

Ortega y Gasset, J. (1947). Obras Completas (Vol. IV). Madrid: Revista de Occidente.

Pérez Díaz, V. (2006). Formas modernas de la libertad y virtudes antiguas. ASP Research Paper, 60(a). 
Pleyers, G. y Álvarez-Benavides, A. (2019). La producción de la sociedad a través de los movimientos sociales. Revista Española de Sociología, 28(1), 141-149.

Puddington, A. (s. f.). Freedom in the World 2011. The Authoritarian Challenge to Democracy. Recuperado de https://freedomhouse.org/report/freedom-world/freedom-world-2011

Puddington, A. y Roylance, T. (2015). Freedom in the World 2016. Anxious Dictators, Wavering Democracies: Global Freedom under Pressure. Recuperado de https://freedomhouse. org/report/freedom-world/freedom-world-2016

Puddington, A. y Roylance, T. (2016). Freedom in the World 2017. Populists and Autocrats: The Dual Threat to Global Democracy. Recuperado de https://freedomhouse.org/report/ freedom-world/freedom-world-2017

Renzo, M. (2015). Human Rights and the Priority of The Moral. Social Philosophy \& Policy, 32(1), 127-148. https://doi.org/10.1017/S0265052515000102

Riedel, R. (2017). Populism and Its Democratic, Non-Democratic, and Anti-Democratic Potential. Polish Sociological Review, 199(3), 287-298.

Riesman, D. (1950). The Lonely Crowd: A Study of the Changing American Character. New Haven: Yale UP.

Romanos, E. (2018). Del 68 al 15-M: continuidades y rupturas entre ciclos de protesta. Arbor, 194(787), a430. https://doi.org/10.3989/arbor.2018.787n1003

Rosa, H. (2016). Alienación y aceleración. Hacia una teoría crítica de la temporalidad en la modernidad tardía. Buenos Aires: Katz.

Rosanvallon, P. (2007). La contrademocracia. La política en la era de la desconfianza. Buenos Aires: Manantial.

Rose, N. (2007). Politics of life itself: biomedicine, power and subjectivity in the twenty-first century. Princeton: Princeton UP.

Sánchez-Prieto, J. M. (2013). Los desafíos del 'giro performativo': el modelo de Alexander y la pervivencia de Turner. En F. Oncina y E. Cantarino (coords.), Giros narrativos e historias del saber (pp. 77-110). Madrid: Plaza y Valdés.

Sánchez-Prieto, J. M. (2014). Herbert Marcuse y el espíritu neorromántico de la protesta. En C. Sánchez Capdequí (coord.), El dinamismo de los valores. Crisis y creatividad en la sociedad moderna (pp. 53-94). Barcelona: Anthropos.

Schapals, A., Bruns, A. y McNair, B. (eds.), (2019). Digitizing Democracy. Nueva York: Routledge.

Scott, A. (2018). (Plebiscitary) leader democracy. Thesis Eleven, 148(1), 3-20. https://doi. org/10.1177/0725513618800120

Shin, S. (2017). Transhumanism and the Biopolitics of Human Enhancement. Korean Journal of Japanese Studies, 17, 72-95.

Sintomer, Y. (2017). ¿Condenados a la posdemocracia? Nueva Sociedad, (267), 22-34.

Son, H. (2019). Artificial Intelligence Governance and the Future of Democracy. Journal of Social Thoughts and Culture, 2, 305-349.

Sparke, M. (2017). Austerity and the embodiment of neoliberalism as ill-health: Towards a theory of biological sub-citizenship. Social Science \& Medicine, 187, 287-295. https://doi.org/10.1016/j.socscimed.2016.12.027 
Stone, L. (2019). From ethics to ethics: Combatting dangers to democracy. Ethics and Education, 14(2), 143-156.

Stow, S. (2017). American Mourning: Tragedy, Democracy, Resilience. Cambridge: Cambridge UP.

Sunstein, C. (2017). \#Republic: Divided Democracy in the Age of Social Media. Princeton: Princeton UP.

Sunstein, C. (2018). Is Social Media Good or Bad for Democracy? SUR International Journal on Human Rights, 27, 83-89.

The retreat of global democracy stopped in 2018. (8 de enero de 2019). The Economist. Recuperado de https://www.economist.com/graphic-detail/2019/01/08/the-retreat-ofglobal-democracy-stopped-in-2018

Todorov, T. (2012). Los enemigos íntimos de la democracia. Barcelona: Galaxia Gutenberg.

Tormey, S. (2015). The End of Representative Politics. Cambridge: Polity.

Ungureanu, C. y Serrano, I. (2018). El populismo como relato y la crisis de la democracia representativa. Revista Cidob d'Afers Internationals, 119, 13-33. https://doi.org/10.24241/ rcai.2018.119.2.13

Valadier, P. (2017). La posverdad, peligro para la democracia. Revista de Fomento Social, 286, 297-304. https://doi.org/10.32418/rfs.2017.286.1426

Vallor, S. (2016). Technology and the Virtues: A Philosophical Guide to a Future Worth Wanting. Oxford: Oxford UP.

Vermeulen, B., Kesselhut, J., Pyka, A. y Saviotti, P. P. (2018). The Impact of Automation on Employment: Just the Usual Structural Change? Sustainability, 10(5), 1661. https://doi.org/10.3390/su10051661

Vodovnik, Z. (2017). The Blue Note of Democracy. Teorija in Praksa, 54(1), 5-16.

Weitzel, M. (2019). Engineering Affect. Street Politics and Microfoundations of Governance. Middle East Law and Governance, 11(2), 203-243. https://doi.org/10.1163/1876337501102005

Wirz, D. (2018). Persuasion through Emotion? An experimental test of the emotion-eliciting nature of populist communication. International Journal of Communication, 12, 11141138. https://doi.org/10.5167/uzh-149959

Zizek, S. (2005). La suspensión política de la ética. Buenos Aires: FCE.

\section{NOTA BIOGRÁFICA}

Juan María Sánchez-Prieto es Doctor en Historia, Profesor Titular de Sociología en la Universidad Pública de Navarra, y está acreditado por la ANECA como Catedrático de Universidad. Es además director de I-COMMUNITAS: Institute for Advanced Social Research (UPNA). Su investigación está centrada en el campo de las ideologías y las representaciones colectivas, entendidas en el marco más amplio de las culturas políticas y la performatividad social. Junto a numerosos artículos de revista y contribuciones a obras colectivas, es autor de los libros El imaginario vasco (Barcelona, 1993), La España plural (Bilbao, 1999) y Navarra: memoria, política e identidad (Pamplona, 2005), este último 
Democracia y creatividad. El nuevo horizonte de la política en el siglo XXI

en colaboración con José Luis Nieva. Es autor asimismo de dos extensos estudios sobre las figuras de Donoso Cortés (2003) y Alcalá Galiano (2008). Ha coordinado también dos volúmenes de referencia: uno en la Revista Anthropos (núm. 223, 2009) sobre Reinhart Koselleck y la investigación de la historia conceptual; y otro en la revista Arbor del CSIC (Vol. 194, núm. 787, 2018) sobre «El 68: mito y crítica», con ocasión del cincuentenario. 